\title{
Kernos
}

Revue internationale et pluridisciplinaire de religion grecque antique

33 | 2020

Varia

\section{Feasting and Polis Institutions}

\section{Zoé Pitz}

\section{OpenEdition \\ Journals}

Édition électronique

URL : https://journals.openedition.org/kernos/3581

DOI : 10.4000/kernos.3581

ISSN : 2034-7871

\section{Éditeur}

Centre international d'étude de la religion grecque antique

\section{Édition imprimée}

Date de publication : 31 décembre 2020

Pagination : 337-338

ISBN : 978-2-87562-264-8

ISSN : 0776-3824

\section{Référence électronique}

Zoé Pitz, «Feasting and Polis Institutions », Kernos [En ligne], 33 | 2020, mis en ligne le 31 décembre 2020, consulté le 06 décembre 2022. URL : http://journals.openedition.org/kernos/3581 ; DOI : https:// doi.org/10.4000/kernos.3581

Ce document a été généré automatiquement le 6 décembre 2022.

Tous droits réservés 


\section{Feasting and Polis Institutions}

\section{Zoé Pitz}

\section{RÉFÉRENCE}

Floris VAN DEN EJjNDE, Josine H. BLoK, Rolf stRootman (dir.), Feasting and Polis Institutions, Leiden/Boston, Brill, 2018. 1 vol. 15,8 $\times 24 \mathrm{~cm}$, xiii+384 p. (Mnemosyne Supplements, 414). ISBN : 978-90-04-35672-6.

1 Feasting and Polis Institutions rassemble les actes d'un colloque du même nom organisé à l'Université d'Utrecht du 16 au 19 janvier 2014. Cet ouvrage vise à comprendre comment deux formes particulières de fêtes - la fête sacrificielle et le symposion - ont émergé et évolué dans le monde grec, mais aussi et surtout comment elles se sont placées au cœur des institutions religieuses et politiques qui définissent la société grecque. Les différentes contributions proposées se fondent sur des sources anciennes diversifiées et analysent des pratiques de commensalité allant du début de l'âge du Fer à l'époque impériale, en poursuivant l'objectif commun de mieux saisir les relations de pouvoir qui se tissent en contexte festif.

2 L'article d'A. Alexandridou porte sur la fonction de la "Sacred House ", un complexe architectural attique du début de l'âge du Fer mis au jour sur le site occupé plus tard par l'Académie de Platon. La réévaluation des données anciennes et la découverte de nouveau matériel céramique à cet endroit suggèrent que ce complexe n'accueillait pas des activités cultuelles ni funéraires, mais constituait un groupe d'habitat comprenant des résidences et des salles où se déroulaient des banquets domestiques. F. van den Eijnde s'interroge sur la manière dont les changements dans la pratique festive font écho aux transformations sociales observées en Attique entre la chute du monde palatial et l'avènement de la polis (ca. 1100-600 av. J.-C.). Outre les raisons de ces changements et la manière dont ils se sont mis en place, l'A. envisage leurs implications en ce qui concerne les rôles de patronage, les éléments qui caractérisent les participants comme membres d'une communauté ainsi que les structures de pouvoir plus larges que ces modifications reflètent. $-\mathrm{V}$. Vlachou analyse les restes de vaisselle 
en céramique associés à la consommation de nourriture et de boissons qui ont pu être mis au jour dans le sanctuaire d'Apollon Hyakinthos à Amyclées, au sud-est de Sparte. Par l'examen de ces données matérielles, l'A. tente de comprendre les transformations opérées dans l'activité et la structure rituelles de ce sanctuaire entre la fin de l'âge du Bronze et le début de l'âge du Fer. - J. Whitley et R. Madgwick présentent les résultats de l'analyse des ossements d'animaux mis au jour à Praisos (Crète) en 2007, à proximité d'une structure découverte par R.C. Bosanquet en 1901 et qualifiée indifféremment d'« Almond Tree House » ou d'" Andreion ». De même que la concentration de coupes et la proximité d'un bâtiment classique plutôt raffiné, la présence de squelettes de moutons presque entiers et le pourcentage inhabituel d'animaux sauvages dans le dépôt supérieur suggèrent que les dépôts en question constituaient des restes de banquets ritualisés liés à l'institution de l'andreion. - S. Lambert aborde la sociologie des modalités de financement des sacrifices de la Tétrapole de Marathon, et ce dans le contexte plus large du système de financement sacrificiel athénien. L'analyse, proposée à la suite de quelques observations sur la religion de la Tétrapole et sur son imbrication dans la vie et les préoccupations d'une communauté locale agricole, est fondée sur l'édition du calendrier sacrificiel élaborée précédemment par l'A. - J. Blok et E. van't Wout proposent une nouvelle analyse du plus ancien document public athénien attestant la pratique de la sitēsis, c'est-à-dire le privilège d'être nourri toute sa vie au Prytanée après avoir contribué de manière exceptionnelle à la prospérité du peuple (IG $\left.\mathrm{I}^{3} 131\right)$. Le réexamen de ce document, qui règlemente les critères d'éligibilité à cette institution honorifique, comprend notamment une nouvelle version du texte et une traduction anglaise. - A. Steiner présente les premiers résultats d'une étude en cours portant sur le matériel céramique provenant de la Tholos d'Athènes, un lieu où les prytanes se réunissaient pour manger et boire ensemble. L'examen des sources montre comment le principe d'isonomia, articulé à travers les réformes d'Éphialte en $462 / 1$, se reflétait dans la prise de repas communs par les prytanes à cet endroit. $K$. Lynch étudie l'évolution des pratiques symposiaques à Athènes, en s'appuyant sur des fragments de vaisselle en céramique mis au jour lors des fouilles de l'agora. L'A. envisage les hypothèses permettant d'expliquer pourquoi les symposia archaïques et classiques, où tous les participants étaient égaux et où la consommation de vin était prédominante, ont fait place, à la période hellénistique, à des banquets riches en nourriture permettant de mettre en évidence le statut et les moyens financiers de l'hôte. - La contribution de M. Wecowski porte également sur la pratique symposiaque, et plus particulièrement sur la question de son déclin. Selon l'A., le symposion, qui était une institution fondamentale aux périodes archaïque et classique et jouait le rôle de "banquet culturel ", a commencé à décliner au milieu du $\mathrm{IV}^{\mathrm{e}}$ siècle en raison de certains changements culturels importants observés à la fin du ve siècle. - R. Strootman cherche à comprendre comment les souverains macédoniens ont réussi à acquérir une place dans les cités grecques grâce aux fêtes, en dépit du fait qu'ils n'étaient pas citoyens des poleis qu'ils visitaient et que, particulièrement au début de la période hellénistique, un sentiment pro-démocratique et anti-tyrannique était répandu dans les cités. - M. Mari analyse l'influence de l'héritage macédonien sur certains traits des habitudes festives hellénistiques, et plus particulièrement sur des aspects étudiés dans ce volume : les banquets, les fêtes publiques, les grands sacrifices et la distribution de nourriture. Bien qu'il soit important dans ce domaine comme dans d'autres aspects de l'histoire culturelle et sociale du monde hellénistique, l'arrière-plan macédonien ne suffit pas à expliquer la variété, la complexité et les innovations profondes observées à 
cette période. - Les deux dernières contributions de l'ouvrage, celles de S. Paul et de J.-M. Carbon, proposent des réflexions tirées d'une présentation sur la division sacrificielle réalisée conjointement pour le colloque d'Utrecht. S. Paul analyse les aspects pratiques de la division dans les rituels civiques à la période hellénistique. Plus particulièrement, l'A. se concentre sur deux actions qui se situent respectivement au début et à la fin d'une fête sacrificielle: la procession et la distribution de viande. Plusieurs passages de normes rituelles sont analysés afin de tenter de comprendre s'il existait une correspondance entre la participation à la procession et le droit de recevoir des portions de l'animal mis à mort. - J.-M. Carbon s'intéresse quant à lui aux parts de viande attribuées aux destinataires de décrets honorifiques, principalement aux périodes hellénistique et romaine. Les inscriptions analysées montrent que ces individus inclus dans la division sacrificielle en guise de marque de distinction n'étaient pas nécessairement présents lors du sacrifice, et que les parts d'honneur qui leur revenaient leur étaient parfois envoyées chez eux. Ainsi, même à distance, un geras de viande liait concrètement l'individu honoré à la communauté sacrifiante et à la sphère divine.

\section{AUTEURS}

\section{ZOÉ PITZ}

Collège de France - Bourse Anna Caroppo 